\title{
Study on Rail Short-Wave Irregularity of Speed Increased Tracks
}

\author{
Jian FANG ${ }^{\mathrm{a}}$, Xiaoyan LEI ${ }^{\mathrm{a}, 1}$, Songliang LIAN ${ }^{\mathrm{b}}$, and Wenwen ZHENG ${ }^{\mathrm{a}}$ \\ ${ }^{a}$ Engineering Research Center of Railway Environment Vibration and Noise of the \\ Ministry of Education, East China Jiaotong University, Nanchang, Jiangxi Province \\ 330013, China \\ ${ }^{b}$ School of Transportation Engineering ,Tongji University, Shanghai, 201804, China
}

\begin{abstract}
The data obtained from a field test of irregularity of rail surface in $\mathrm{Hu}$ Kun line, a CWR track, is processed by statistical analysis of maximum amplitude and one-third octave analysis. The result shows that the regularities of rail surface in joint areas of CWR track are worse in common. In general, the amplitudes of rail surface irregularities can get beyond $0.5 \mathrm{~mm} / \mathrm{m}$, which exceed standard values in every wave length ranges, and the maximum of them can reach $15 \mathrm{~dB}$. The conditions of rail surface regularities in non-joint areas are better, and the rail surface irregularities from most of the test points are lower than $0.15 \mathrm{~mm} / \mathrm{m}$, which do not exceed standard values.
\end{abstract}

Keywords. Speed increased track, rail surface, short wave irregularity, field test

\section{Introduction}

During the process of trains running, the rail will generate many kinds of geometrical irregularities and rail surface irregularities. Literatures [1-4] from home and abroad show that long wave irregularities will influence the stability of vehicles; middle wave not only the accelerations of vehicles vibration, but also the wheel/rail forces; short wave mainly wheel/rail forces and generates wheel/rail noise. Moreover huge wheel/rail forces produce vibration of vehicles in high frequencies when trains run $[5,6]$. Generally long wave length ranges from several meters to dozens of meters and middle wave length from $1 \mathrm{~m}$ to several meters and short wave length from several centimeters to dozens of centimeters [7]. The statuses of sub-rail base worsen lead to long wave irregularities and asymmetry abrasions of rail surface will lead to short wave irregularities. Middle wave irregularities come from both of the two situations above. Meanwhile, the rail surface irregularities whose wave length range from a fraction of millimeter to several millimeters will influence wheel rolling noise [8].

In this paper through field test of rail surface irregularities at Pujiang station in $\mathrm{Hu}-$ Kun Line, the distribution characteristics of rail surface short wave irregularities is discussed. And this will provide technical basis for understanding and controlling short wave irregularities.

1 Lei Xiaoyan, Engineering Research Center of Railway Environment Vibration and Noise of the Ministry of Education, East China Jiaotong University, Nanchang Jiangxi Province 330013, China; E-mail: xiaoyanlei2013@163.com 


\section{Test Evaluation Standards of Rail Surface Short Wave Irregularities}

There are a few of standards to evaluate rail surface irregularities and it is only Eurail that has made rail surface irregularities standard EN: ISO 3095:2005(E) [9, 10] in studying wheel/rail noise.

\subsection{Calculations of Rail Surface Irregularities}

In the standard of EN: ISO-3095-2005, the calculations of rail surface irregularities have been represented in detail. Firstly, the mean square roots (the unit is $\mu m$ ) of test value are computed, then rail surface irregularities are counted according to the formula as follows:

$$
\begin{aligned}
& L_{r}=20 \log \left(\frac{r}{r_{0}}\right)(\mathrm{dB}) \\
& L_{r}: \text { irregularity }(\mathrm{dB}) ; \\
& r: \text { RMS of wheel tread and rail surface irregularities }(\mu m) ; \\
& r_{0}: \text { reference irregularities, } r_{0}=1 \mu m .
\end{aligned}
$$

\subsection{Wheel Tread and Rail Surface Irregularities (roughness) Standard Values}

Limit values of rail surface roughness in ISO 3095-2005 are shown in Table 1.

Table 1. ISO-3095: 2005 (E) Limit values of rail surface roughness

\begin{tabular}{|l|l|l|l|l|l|l|l|l|l|l|l|}
\hline $\begin{array}{l}\text { Wave } \\
\text { length(cm) }\end{array}$ & 0.315 & $\begin{array}{l}0.40 \\
0\end{array}$ & 0.500 & 0.630 & 0.800 & 1.000 & 1.250 & 1.600 & 2.000 & 2.500 & 3.150 \\
\hline $\begin{array}{l}\text { Irregularities } \\
\text { (dB) }\end{array}$ & $\begin{array}{l}9.70 \\
0\end{array}$ & $\begin{array}{l}9.70 \\
0\end{array}$ & 9.700 & 9.700 & 9.700 & 9.700 & 7.800 & 6.000 & 4.100 & 2.300 & 0.500 \\
\hline $\begin{array}{l}\text { Wavelength } \\
\text { (cm) }\end{array}$ & 4.000 & $\begin{array}{l}5.00 \\
0\end{array}$ & 6.300 & 8.000 & $\begin{array}{l}10.00 \\
0\end{array}$ & 12.500 & 16.000 & $\begin{array}{l}20.00 \\
0\end{array}$ & 25.000 & 31.500 & $\begin{array}{l}40.00 \\
0\end{array}$ \\
\hline $\begin{array}{l}\text { Irregularities } \\
\text { (dB) }\end{array}$ & 1.400 & $\begin{array}{l}3.20 \\
0\end{array}$ & 5.100 & 6.900 & 8.800 & 10.600 & 12.400 & $\begin{array}{l}14.30 \\
0\end{array}$ & 16.100 & 18.000 & $\begin{array}{l}19.80 \\
0\end{array}$ \\
\hline
\end{tabular}

In consideration of the lack of roughness standards of wheel tread and rail surface in China's railway, this paper adopts ISO 3095: 2005(E) to evaluate and analysis rail surface irregularities.

\section{Field Test of Rail Surface Irregularities}

Hangzhou Railway Section, Shanghai Railway Administration, carried out field tests of rail surface irregularities on the left side of No.14-17 rail in K294 in uplink and No.418 rail in K294 in downlink at Pujiang Station in Hu-Kun Line.

\subsection{Test Instrument}

SEC-RC rail electric flatness gauge, produced by Schmidt rail technology Co., LTD and whose sampling interval was 200 testing point per meter, was used. The test instrument is shown in Figure 1. 


\subsection{Test Content}

In order to analyze rail surface regularities from different parts of the rail, rail surface regularities data mainly obtained from middle-rail (1/2 standard rail length apart from rail welding joint) and side-rail (1/4 and 3/4 standard rail length apart from welding joint) was collected. There were 4 testing points ( 1 point in joint, 1 point in middle-rail, 2 points in side-rail) in every rail, and 104 samples. The situation of the field test is shown in Figure1.

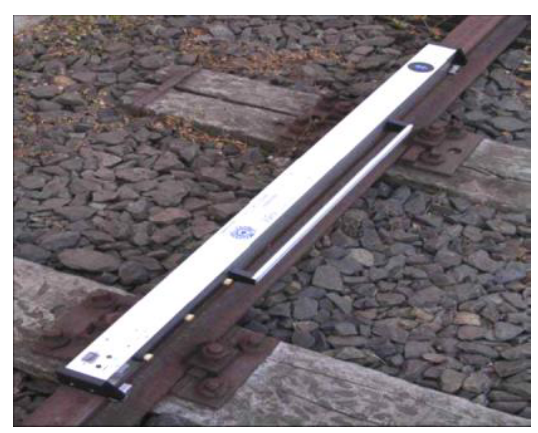

Figure 1. Rail electric flatness gauge.

\section{Analysis of Rail Surface Irregularities}

\subsection{Waveform Classification}

According to collected data, rail surface short waves are divided into 3 categories to convenient to analysis: single convex wave, single spill wave and short resonance wave, as shown in Figure 2-4.

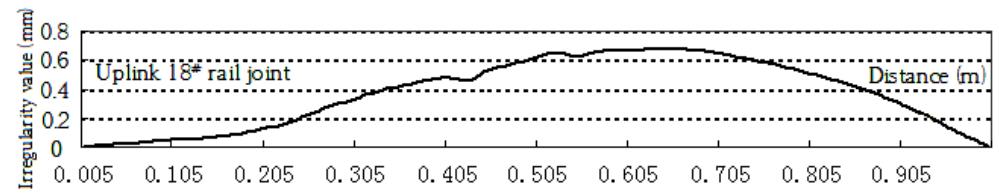

Figure 2. Single convex irregularities wave.

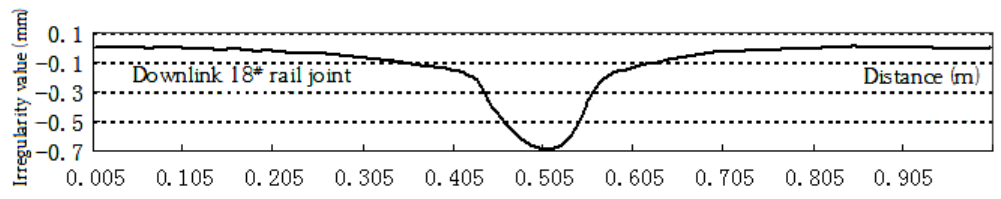

Figure 3. Single spill irregularities wave.

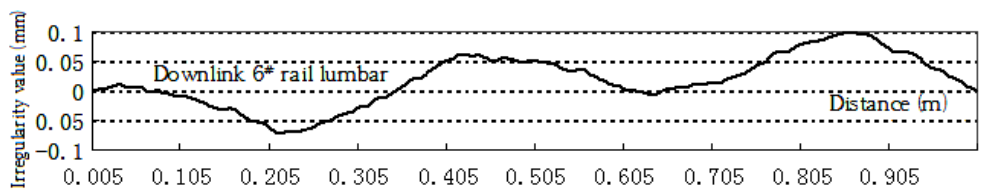

Figure 4. Irregularities wave of resonance. 


\subsection{Statistical Analysis}

Maximum and minimum values of every testing sample are produced in statistical analysis to find out the difference of rail surface regularities in joint and non-joint areas.

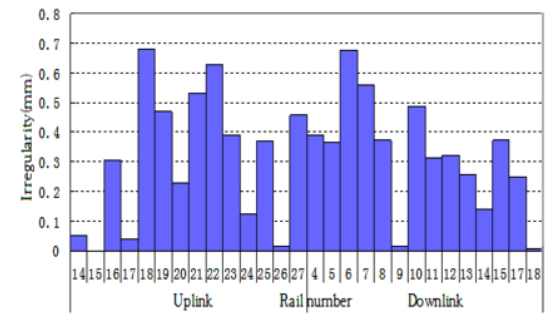

(a) scattergram along the line.

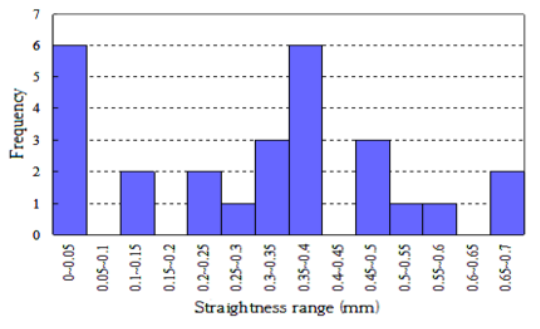

(b) frequency column diagram.

Figure 5. Scattergram of max convex irregularities in joint areas.

Figure 5(a) shows the max convex irregularities of rail surface in joint areas, and Figure 5(b) the frequency of max irregularities. As can be seen in Figure 5, the max convex irregularities of rail surface is $0.68 \mathrm{~mm}$, which allocates mainly in $0-0.05 \mathrm{~mm}$ and $0.3-0.4 \mathrm{~mm}$, and the mean value is $0.314 \mathrm{~mm}$.

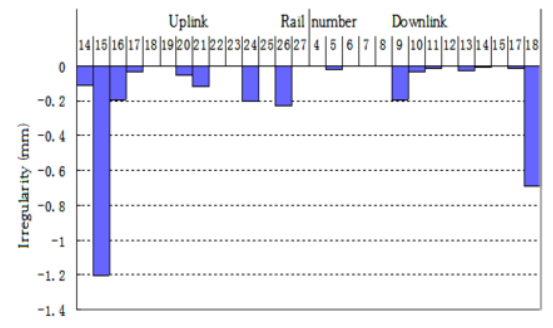

(a) scattergram along the line.

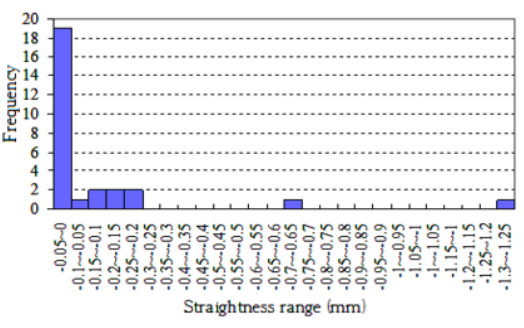

(b) frequency column gram.

Figure 6. Scattergram of max spill irregularities in joint areas.

Figure 6(a) shows the max spill irregularities of rail surface in joint areas, and Figure 6(b) the frequency of max irregularities. In Figure 7, the max spill irregularities is $-1.2 \mathrm{~mm}$, which allocates mainly in $-0.05-0 \mathrm{~mm}$, greater than max convex irregularities $(0.68 \mathrm{~mm})$, and the mean value is $-0.11 \mathrm{~mm}$.

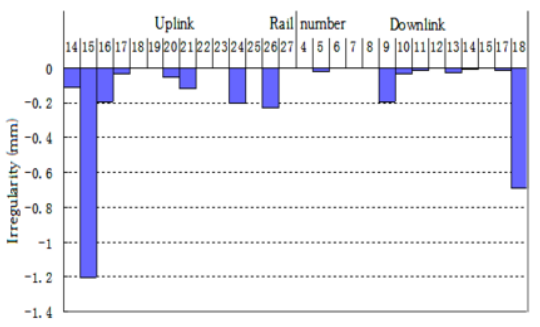

(a) scattergram along the line.

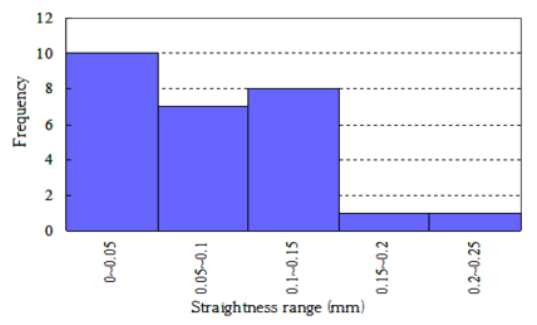

(b) frequency column gram.

Figure 7. Scattergram of the max convex irregularities at side-rail 1. 
Figure 7(a) shows max convex irregularities at side-rail 1, Figure 7(b) max frequency irregularities. In Figure8, the max convex irregularity of rail surface at siderail is $0.28 \mathrm{~mm}$, most of which is less than $0.15 \mathrm{~mm}$, and the mean value is $0.074 \mathrm{~mm}$. It means that the convex irregularities of rail surface at side-rail 1 are good.

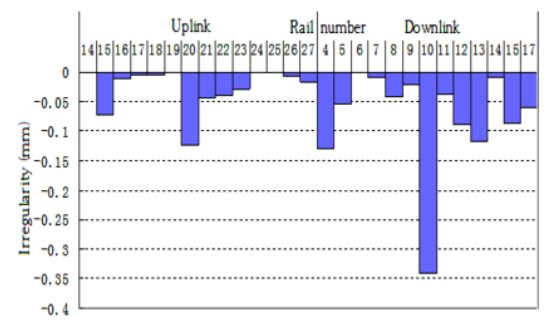

(a) scattergram along the line.

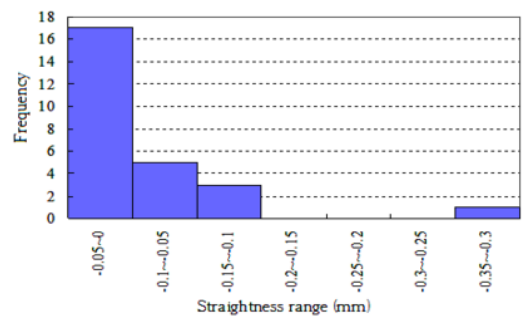

(b) frequency column gram.

Figure 8. Scattergram of the max spill irregularities at side-rail 1.

Figure 8(a) shows the max spill irregularities of rail surface at side-rail 2, Figure 8(b) the max frequency irregularities. In Figure8, the max spill irregularity of rail surface at side-rail 2 is $0.35 \mathrm{~mm}$, greater than $0.28 \mathrm{~mm}$, the max convex irregularity at side-rail 1 , and the mean value is $0.052 \mathrm{~mm}$, most of which is less than $0.05 \mathrm{~mm}$.

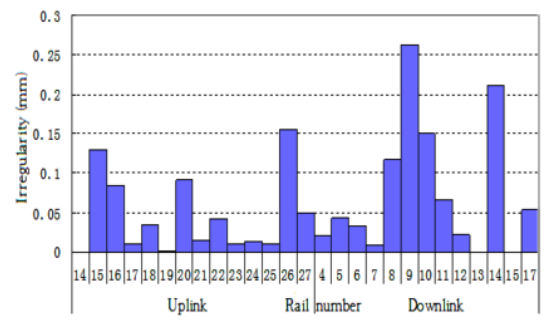

(a) scattergram along the line.

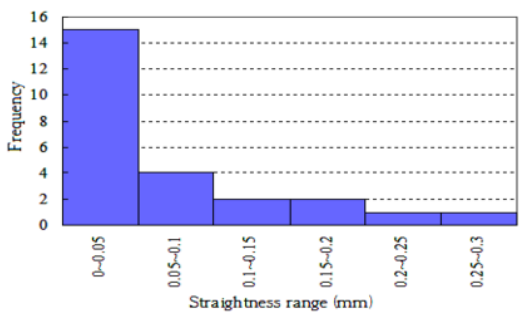

(b) frequency column gram.

Figure 9. Scattergram of the max convex irregularities at side-rail 2.

Figure 9(a) shows the max convex irregularities of rail surface at side-rail 2, Figure 9(b) the max frequency irregularities. In Figure 9, the max convex irregularity of rail surface at side-rail 2 is $0.27 \mathrm{~mm}$, most of which is less than $0.05 \mathrm{~mm}$, and the mean value is $0.065 \mathrm{~mm}$.

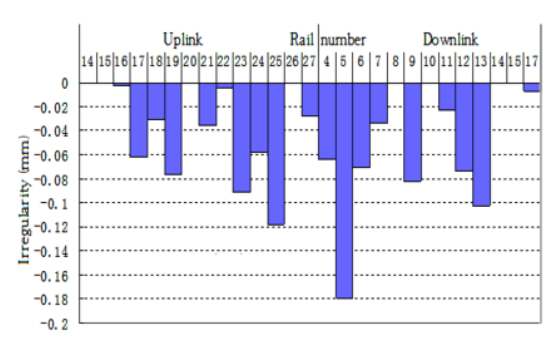

(a) scattergram along the line.

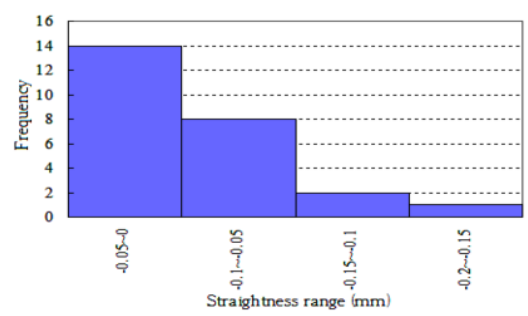

(b) frequency column gram.

Figure 10. Scattergram of the max spill irregularities at side-rail 2. 
Figure 10 shows the max spill irregularities of rail surface at side-rail 2, Figure 10 the max frequency irregularities. In Figure10, the max spill irregularity of rail surface at side-rail 2 is $0.18 \mathrm{~mm}$, most of which is less than $0.1 \mathrm{~mm}$. The value less than $0.05 \mathrm{~mm}$ is of the most. The mean value is $0.046 \mathrm{~mm}$.

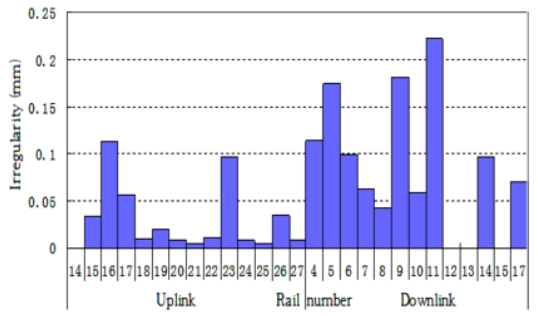

(a) scattergram along the line.

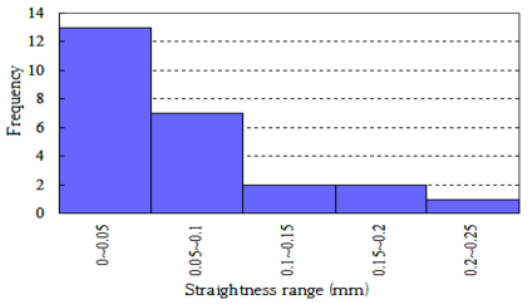

(b) frequency column gram.

Figure 11. Scattergram of the max convex irregularities at middle-rail.

Figure 11(a) shows the max convex irregularities of rail surface at middle-rail, Figure 11(b) the max frequency irregularities. In Figure11, the max convex irregularity of rail surface at middle-rail is $0.23 \mathrm{~mm}$, most of which is less than $0.1 \mathrm{~mm}$, and the mean value is $0.061 \mathrm{~mm}$.

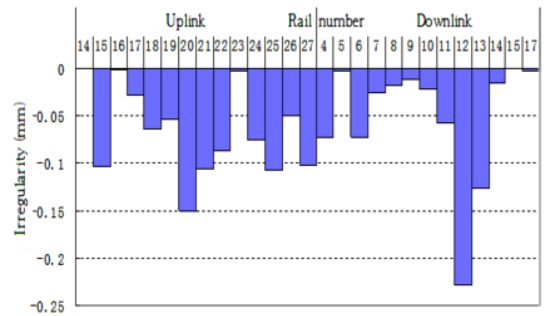

(a) scattergram along the line.

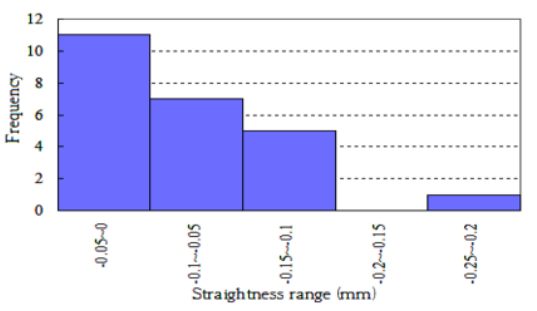

(b) frequency column gram.

Figure 12. Scattergram of the max spill irregularities at middle-rail.

Figure 12(a) shows the max spill irregularities of rail surface at middle-rail, Figure 12(b) the max frequency irregularities. In Figure 12, the max spill irregularity of rail surface at middle-rail is $0.23 \mathrm{~mm}$, most of which is less than $0.15 \mathrm{~mm}$, and the mean value is $0.064 \mathrm{~mm}$.

The ranges of the max and mean rail surface irregularities can be obtained by statistical analysis of rail surface irregularities of every sample. As shown in Table 2:

Table 2. Statistical of the max irregularities of rail surface

\begin{tabular}{|l|l|l|l|l|}
\hline Parts of the rail & Styles & Max $(\mathrm{mm})$ & Mean $(\mathrm{mm})$ & Ranges(mm) \\
\hline \multirow{2}{*}{ Joint } & Convex & 0.68 & 0.314 & $0 \sim 0.005, \quad 0.3 \sim 0.4$ \\
\cline { 2 - 5 } & Spill & 1.20 & 0.110 & $0 \sim 0.05$ \\
\hline \multirow{2}{*}{ Side-rail 1 } & Convex & 0.28 & 0.074 & $0 \sim 0.15$ \\
\cline { 2 - 5 } & Spill & 0.35 & 0.052 & $0 \sim 0.05$ \\
\hline \multirow{2}{*}{ Side-rail 2 } & Convex & 0.27 & 0.065 & $0 \sim 0.05$ \\
\cline { 2 - 5 } & Spill & 0.18 & 0.046 & $0 \sim 0.05$ \\
\hline \multirow{2}{*}{ Middle-rail } & Convex & 0.23 & 0.061 & $0 \sim 0.1, \quad 0 \sim 0.05$ \\
\cline { 2 - 5 } & Spill & 0.23 & 0.064 & $0 \sim 0.15, \quad 0 \sim 0.05$ \\
\hline
\end{tabular}


Considering the max irregularities, Table 2 shows that regularities in joints are worse than what in side-rail and middle-rail; convex irregularities worse than spill irregularities; irregularities in side-rail 1 worse than irregularities in side-rail 2; regularities in side-rail worse than in middle-rail.

\subsection{1/3 Octave Analysis of Rail Surface Irregularities}

In order to analyze the distribution of irregularities waves of rail surface, $1 / 3$ octave analysis and statistics of irregularities data from joints, side-rails and middle-rail are carried out, and make a contract to the limit values in ISO 3095: 2005(E).

\subsubsection{1/3 Octave Spectrum Analysis of Rail Surface Regularities in Joints}

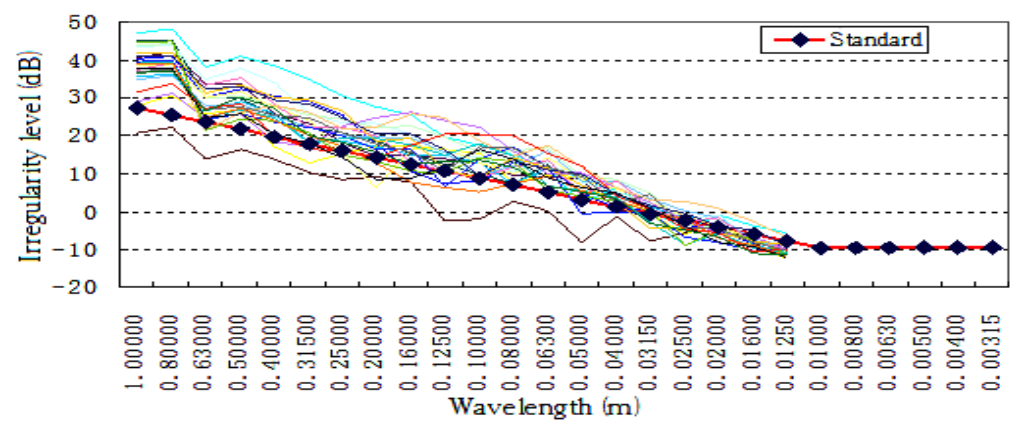

Figure 13. 1/3 octave spectrum of rail surface irregularities in joints.

Figure 13 is $1 / 3$ octave spectrum of rail surface irregularities in joints. It shows that the irregularities of the rail joints are higher than standard limit values, the max difference of which is $18 \mathrm{~dB}$, and the regularity of the rail surface is low. Moreover, in different range of frequency, irregularities of rail surface are different. In the wavelength range of $0.05-1 \mathrm{~m}$, the irregularities of the rail surface are high, and increase as the wavelength increases. In the wavelength range of less than $0.05 \mathrm{~m}$, the irregularities are low and close to standard values, and decrease to standard values as the wavelength decreases.

\subsubsection{1/3 Octave Spectrum Analysis of Rail Surface Regularities at Side Rails}

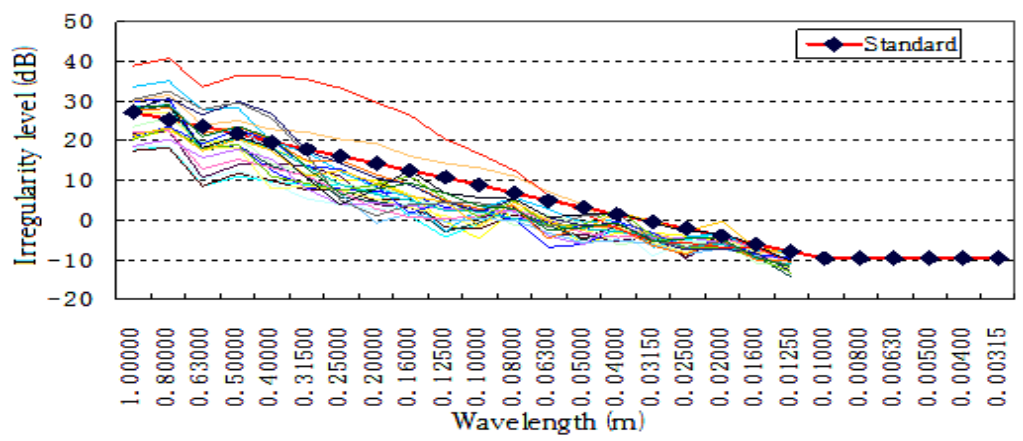

Figure 14. 1/3 octave spectrum of rail surface irregularities at side-rail 1. 


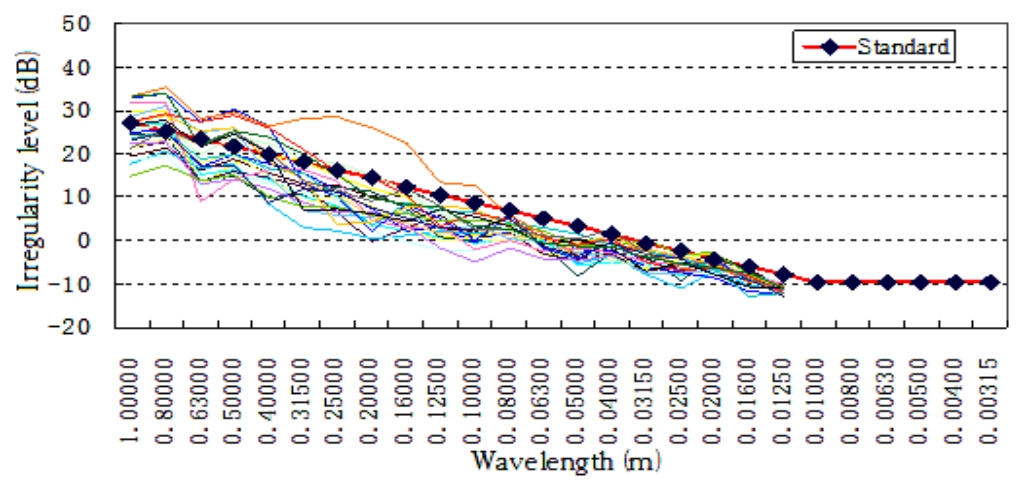

Figure 15. 1/3 octave spectrum of rail surface irregularities at side-rail 2.

Figure 14 and Figure 15 are 1/3 octave spectrums of rail surface irregularities at siderails. They show that, except several points, regularities at side-rail 1 and at side-rail 2 are almost the same. Irregularities are mainly lower than standard spectrum, and the regularities of the track are well. In the range of $0.4-1.0 \mathrm{~m}$, some of them exceed the standard values. But overall, the regularities of rail surface at side-rail are well.

\subsubsection{1/3 Octave Spectrum Analysis of Rail Surface at Middle Rail}

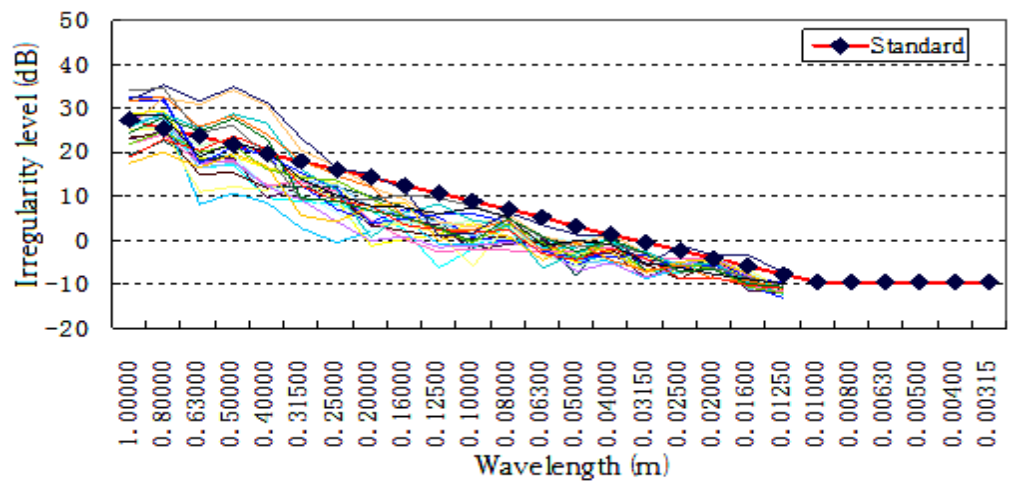

Figure 16. 1/3 octave spectrum of rail surface at middle-rail.

Figure 16 is $1 / 3$ octave spectrum of rail surface at middle-rail. It shows that irregularities of the track are lower than standard values in all the analysis wavelength ranges. In the range of $0.315-1.0 \mathrm{~m}$, some of them are higher than standard. But overall, the regularities of rail surface at side-rail are well.

\section{Conclusions}

Based on the analysis of the rail surface irregularities data from the field test, some conclusions can be drawn:

(1)The regularities of rail surface in welding joints are low commonly. In spite of contact bond joints, their rail surface regularities are lower than non-joint areas. Generally, the rail surface irregularities in welding joints can reach beyond $0.5 \mathrm{~mm} / \mathrm{m}$. 
(2)The rail surface regularities in non-joint areas are high commonly. They are less than $0.15 \mathrm{~mm} / \mathrm{m}$ in most testing points, and some of them reach $0.2 \mathrm{~mm} / \mathrm{m}$.

(3)According to $1 / 3$ octave analysis, the rail surface irregularities in welding joints are higher than standard values in EN: ISO-3095-2005 in every wave range. Max irregularity is $15 \mathrm{~dB}$ higher than standard values, and it is $5 \mathrm{~dB}$ higher in general.

(4)The rail surface regularities in non-joint areas are high, and the irregularities are all less than standard values $5 \mathrm{~dB}$ in general and $10 \mathrm{~dB}$ in maximum.

\section{Acknowledgements}

The authors wish to acknowledge the support and motivation provided by Project supported by National Natural Science Foundation, China (Grant No. 51668019), Natural Science Foundation of Jiangxi Province Science and Technology department (No.20171BAB206057) and Science Foundation of Jiangxi Province Education department (No.GJJ180297).

\section{References}

[1] Griefahn B, Marks A, Sibylle Robens. Noise emitted from road, rail and air traffic and their effects on sleeper. Journal of Sound and Vibration ,2006,295:129-140.

[2] Dittrich MG, Janssens MHA. Improve measurement method for railway rolling noise. Journal of Sound and Vibration,2000,231(3):595-609.

[3] Cordier JF, Fodiman P. Experimental characterization of wheel and rail surface roughness. Journal of Sound and Vibration,2000,231(3),667-672.

[4] Li ZW, Lei XY, Gao L. A new method for track short wave irregularity simulation. Journal of Traffic and Transportation Engineering, 2016,16(01):37-45.

[5] Yan ZJ, Gao CX, Xu XD, Liu JC, Sun SC. Time-frequency characteristics analysis of short-wave diseases on periodic track of high-speed railway based on vehicle response. Journal of The China Railway Society,2020,41(01):10-17.

[6] Niu LB, Jin G, Liu JC, Zu HL. Application of the wheel-rail force in track short wave irregularity detection. Railway Engineering,2019,59 (08):133-139.

[7] Xiong LJ, Zhu HT, Wang ZY, Wu WJ, Wei H. Study on improving accuracy of track long-wave irregularity measured by semi-observation method (1). Journal of The China Railway Society, 2019,41(06):130-136.

[8] Zhou Y. Analysis of rail surface roughness level spectrum for urban rail transit. Urban Mass Transit, 2014, 17(4):18-22.

[9] Xu K, Ge F. Study on adjusting track irregularity of integrated ballast bed in urban elevated rail. Journal of the China railway Society,2000,22(5):85-89.

[10] ISO3095. Railway applications-Acoustics-Measurement of noise emitted by rail-bound vehicles, 2005. 